\title{
Updated consensus statement on biological agents for the treatment of rheumatoid arthritis and other rheumatic diseases (May 2002)
}

\author{
D E Furst, F C Breedveld, J R Kalden, J S Smolen, C E Antoni, J W J Bijlsma, \\ G R Burmester, B Cronstein, E C Keystone, A Kavanaugh, L Klareskog
}

Ann Rheum Dis 2002;61 (Suppl II):ii2-ii7

A $\mathrm{S}$ in previous years, the consensus group to consider the use of biological agents was formed by an organising committee constituted of rheumatologists from the Universities of Erlangen, Leiden, and Vienna in Europe in cooperation with universities in the United States, Canada, and Europe. Pharmaceutical industry support was obtained from a number of companies, but these institutions had no part in the decisions about the specific programme or about the academic participants at this conference.

The 158 rheumatologists and bioscientists from 22 countries who attended the consensus conference were chosen from a worldwide group of people felt to have experience or interest in the use of biological agents for the treatment of rheumatoid arthritis (RA) and other rheumatic diseases. Unfortunately, the number of attendees and participants was limited so that not everyone who might have been appropriate could be invited.

Additional information has come to light in the past year, both corroborating the major positive effect these drugs have had in RA and documenting possible new and unexpected adverse events. In addition, the first of a new class of targeted biological agents, interleukin 1 (IL1) blocking agents, has become available. Therefore an update of the previous consensus statement ${ }^{1}$ seems both appropriate and necessary.

In the present update the consensus statement is annotated to document the credibility of the data supporting it as much as possible. This annotation is that of Shekelle et al and is described in appendix $3 .^{2}$ All participants reviewed relevant clinical published articles relating to tumour necrosis factor (TNF) and ILl blocking agents. They were given a draft consensus statement and were asked to revise the document in small discussion groups; open discussion of the revisions led to a final document, representing this updated consensus statement.

\section{General statements}

Individual patients differ in the aggressiveness of their disease and its concomitant structural damage, the effect of their disease on their quality of life, and the symptoms and signs engendered by their disease. All these factors must be examined when considering biological treatment for the patient, as must the toxicity of previous and/or alternative disease modifying antirheumatic drug (DMARD) use.

In general, when measuring response to treatment, the American College of Rheumatology (ACR) response criteria (as a combined index) should not be used in clinical practice to monitor individual response (category $\mathrm{B}$ evidence). ${ }^{3}$ Validated quantitative measures such as the disease activity score (DAS), Health Assessment Questionnaire disease index (HAQ-DI), visual analogue scales (VAS) or Likert scales of global response or pain by the patient or global response by the doctor, joint tenderness and/or swelling counts, and laboratory data all may be used and may be the most appropriate measures for individual patients (category B evidence). ${ }^{3}$ The doctor should consider the patient's response using the above measures to determine the patient's status and improvement.

The use of these drugs will require doctors experienced in the diagnosis, treatment, and assessment of RA and other rheumatic diseases. These doctors will need to make long term observations for efficacy and toxicity.

Because these agents are not free from toxicity, patients or their representatives should be provided with information about potential risks and benefits so that they may give informed consent for treatment.

\section{TNF BLOCKING AGENTS}

TNF blocking agents differ in composition, precise mechanisms of action, pharmacokinetics, biopharmaceutical properties, etc, but this document emphasises areas of commonality. Data which clearly differentiate compounds will be discussed, if such areas exist.

\section{Indications}

TNF blockers are recommended for the treatment of active RA after an adequate trial of another effective DMARD, of which methotrexate (MTX) is a commonly used example (category A evidence). ${ }^{4-18}$ TNF blocking agents can be added to pre-existing treatment, or, when appropriate, may replace previous DMARDs (category A evidence). ${ }^{9-17} 19$ There is evidence that TNF blockers are effective for the treatment of RA in MTX-naive patients (category A evidence). ${ }^{4-11}$ The use of TNF blocking agents as the first DMARD for the treatment of RA (category A evidence) ( $^{9-12}$ should, at present, be limited because these compounds are expensive and one needs to include cost considerations along with those of efficacy, effectiveness, and long term safety. However, patients in whom other DMARDs are relatively contraindicated may be considered for use of TNF blockers as the first DMARD(category D evidence).

One TNF blocking agent has been approved for juvenile idiopathic arthritis of the polyarticular type ${ }^{2021}$ and for psoriatic arthritis ${ }^{22}$ (category A evidence). TNF blocking agents have been shown to be efficacious in ankylosing spondylitis and other spondyloarthropathies (category A evidence) ${ }^{23-26} \mathrm{~A}$ trial of TNF blocker treatment for adult onset Still's disease has been published (category B evidence). ${ }^{27}{ }^{28}$ Anecdotal data

\footnotetext{
Abbreviations: $a C L$, anticardiolipin antibody; $A C R$, American College of Rheumatology; ANA, antinuclear antibody; DAS, disease activity score; DMARD, disease modifying antirheumatic drug; HAQ-DI, Health Assessment Questionnaire disease index; IL, interleukin; MTX, methotrexate; RA, rheumatoid arthritis; TNF, tumour necrosis factor; VAS, visual analogue scale
} 
have been published of its use in Behçet's uveitis and uveitis (category D evidence (letters)). ${ }^{29}{ }^{30}$ It has also been used in Wegener's granulomatosis, Takayasu's arteritis, Sjögren's syndrome, polymyositis, systemic sclerosis, and giant cell arteritis (category D evidence (abstracts)). ${ }^{31-33}$ These compounds may have potential in these and other conditions, although more work is needed in all cases.

Pharmacoeconomic data and long term safety data may change the circumstances when TNF blocking agents will be started.

\section{Clinical use}

TNF blocking agents, when given in adequate doses and sufficiently frequent dosing regimens, should lead to significant, documentable improvement in symptoms, signs and/or laboratory measures within 12 weeks (category A evidence). ${ }^{4-17}$ There is no evidence that any one TNF blocking agent should be used before another one can be tried, just as there is no credible evidence that any TNF blocker is more effective than another (category D evidence (abstracts)). ${ }^{34-39}$ Individually important responses, including patient oriented measures (for example, HAQ-DI, patient's global VAS) or physical measures (for example, joint tenderness), should be demonstrated within 8-12 weeks for RA (category A evidence). ${ }^{4-17}$ If such improvement occurs, treatment should be continued. If patients show no response to these agents, treatment should be stopped. In patients with an incomplete response, observations suggest that increasing the dose or reducing the dosing intervals may provide additional benefit, as may the addition or substitution of other DMARDs or other biological agents (category A evidence ${ }^{10}$; category D evidence (abstracts) $)^{1939}$ ).

There are data showing that TNF blocking agents slow radiographic progression in $\mathrm{RA}^{13} 35$ (category A evidence ${ }^{13}$; category D evidence (abstract $)^{35}$ ). Although in some patients who have only partial clinical response, radiographic progression slows, the long term clinical implications of these changes are unknown. Until the long term implications of slowing radiological damage are clear, radiological changes alone should not determine clinical decision-making.

Some patients inadvertently become pregnant while being treated with TNF blocking therapy. Pharmacovigilance data show that the rate of normal live births, miscarriages, and therapeutic terminations is consistent with reported data for the general population (category $\mathrm{D}$ evidence (abstract)). ${ }^{40}$ However there are insufficient data to advise continuation of anti-TNF therapy if a patient becomes pregnant.

Rare cases of lupus-like disease have occurred in patients receiving TNF blocking agents (all of whom were dsDNA positive), and treatment should be stopped if there is clinical evidence of a lupus-like syndrome (FDA) 11141841 (category C evidence). There is no evidence that patients with RA who had, or develop, a positive antinuclear antibody (ANA), anticardiolipin antibody (aCL) and/or dsDNA are at increased risk for the development of drug induced lupus (FDA) (category $\mathrm{C}$ evidence (FDA $)^{4-79-1421}$; category D evidence (abstracts) $)^{18}$ ).

In clinical studies, injection site reactions and infusion reactions were more common in the treatment groups than the placebo groups (category A evidence). ${ }^{4-17}$

\section{Warnings}

TNF blocking agents should not be started, or should be discontinued, when serious infections occur, including septic arthritis, infected prostheses, acute abscess, osteomyelitis, sepsis, systemic fungal infections, Listeria etc. (FDA) ${ }^{4-17}$ 21 (category B evidence). Treatment with TNF blockers in such patients should only be resumed if the infections have been treated adequately (category D evidence).

Previous tuberculosis may be reactivated in patients given TNF blockers; every patient should be evaluated, including a history and physical examination, for the possibility of latent tuberculosis, and treatment for the possibility of latent tuberculosis should be started according to local recommendations (category $\mathrm{C}$ evidence). ${ }^{42}$ Some authorities suggest that TNF blockers may be started as soon antituberculosis treatment is started, although this approach needs further investigation (category D evidence).

Instances of demyelinating-like disorders have been reported in patients receiving TNF blockers, although it is not known currently if the incidence in patients receiving TNF blockers is different from that of a comparable group of patients with RA not treated with TNF blocking agents $(\mathrm{FDA})^{1844}$ (category C evidence (FDA); category D evidence $^{184143}$ ). These agents should be stopped if a demyelinating-like disorder occurs. Patients with a history of definite demyelinating disease should not receive TNF blocking agents. (category D evidence)

A very few instances of pancytopenia and aplastic anaemia have been reported (category C evidence). ${ }^{181}$ Because the incidence of these adverse effects is not known and their relative frequency compared with the general population is also not known, specific recommendations about monitoring cannot be given at this time. If pancytopenia and/or aplastic anaemia occur, TNF blockers should be stopped and patients evaluated for evidence of other underlying disease and potential relationship with the TNF blockade (category C evidence).

Patients with severe (NYHA class III or IV) congestive heart failure given TNF blockers may have an increased relative risk of worsening congestive heart failure and mortality, and each patient's risk versus benefit should be considered before the use of TNF blocking agents is begun or continued in those circumstances (FDA) (category C evidence).

The long term safety or efficacy of TNF blockers in patients with hepatitis $C$ is not known. Controlled studies are awaited. A short, pilot study of TNF blockade in patients with hepatitis C showed no increased viral load over six months (category D evidence (abstract)). ${ }^{44}$

\section{Precautionary statements}

The safety of TNF blockade is unknown or has not been established in the following situations:

I Lymphoma, lymphoproliferative and other malignancies

2 Chronic infections, including HIV, hepatitis B etc

3 During lactation

4 When using ILl blocking agents and TNF blocking agents together; infections are common and serious infections have occurred and this combination should be used with great caution until new data become available (category D evidence (abstract) $)^{45}$

\section{When using live attenuated vaccines}

Other areas where knowledge is lacking are highlighted in the consensus group's recommendations for areas most urgently requiring further research.

\section{Research questions}

Among a number of potential areas requiring action or further research, or both, the consensus groups felt the following projects or directions were most important in each of four areas: registries, efficacy, toxicity, and general issues.

\section{Registry}

1 Long term registries to monitor the toxicity of biological agents are strongly recommended, requiring a cooperative effort among payers, government, industry, and rheumatologists.

2 It would be appropriate to convene a workshop to create common standards for such registries and to have a forum for comparisons of results. 
3 Registries of pregnancy outcomes in patients receiving antiTNF therapy (and after therapy has ended) should be continued.

4 What standards are required for long term trials and observational studies of TNF blockers? What are the outcomes of such studies in relationship to control subjects not taking TNF blockers?

\section{Efficacy}

1 What are the optimal dosing regimens when using TNF blocking agents?

2 Can one switch from one TNF blocking agent to another with improved response and reduced toxicity (some abstracts indicate that switching seems to be effective for some patients)?

3 What is the effect of addition of DMARDs when there is only a partial response to a TNF blocking agent?

4 Can infliximab be used alone or with DMARDs other than MTX?

5 Are there predictors of response and toxicity for TNF blocking agents?

6 Is there a correlation between radiological effect and long term effectiveness for TNF blocking agents?

7 What are the outcomes of patients treated with TNF blocking agents in whom disease activity persists without joint destruction and where joint destruction is observed with little disease activity?

8 Can TNF blockers be used as induction therapies in conjunction with and continuation of traditional DMARDs?

9 Can biological agents be given at lower than currently used doses and/or at dosing intervals longer than currently used to slow or halt radiographic progression in the absence of an ACR20 response?

\section{Safety}

l Can patients with evidence of prior treated mycobacterial infection, or fungal infection, use TNF blocking agents as safely as patients without such a history?

2 Can TNF blocking agents be used safely in pregnant or lactating women?

3 Do TNF blocking agents affect the efficacy of primary vaccination or the safety of live attenuated vaccination?

4 What is the safety profile of TNF blocking agents during surgery? How does it compare to the safety profile of patients undergoing surgery without concomitant TNF blocker use?

\section{Summary}

TNF blocking agents have proved to be effective DMARDs and are a major advance in the treatment of RA. Their use is expanding to other rheumatic diseases. However, rare to uncommon and unexpected toxicities have been found and others may yet be found during their use. Studies in selected areas of efficacy, toxicity, and general use of TNF blocking agents are needed to help define further the most appropriate use of these agents. Other considerations when using TNF blocking agents in this disease should balance efficacy, toxicity, and cost and recognise that data in subgroups of patients are still being acquired. It is hoped that this statement, which is based upon the best evidence available at the time of its creation and is modified by expert opinion, will facilitate the optimal use of these agents for our patients with RA.

\section{IL1 BLOCKING AGENTS}

To date only one ILl blocking agent (Anakinra) has reached the market and references are therefore to this product. As other agents of this class reach the market, the document below will be changed appropriately, but it may appear somewhat inconsistent at present as attempts are made to separate presumed class characteristics from data relating to this prototypic compound.

\section{Indications}

ILl blocking agents may be used for treatment of active RA, alone or with MTX (category A evidence). ${ }^{46}{ }^{47}$ Despite this evidence, the Anakinra label presently requires its use with MTX in Europe. ILl blocking agents are recommended for the treatment of active RA after an adequate trial of another effective DMARD, of which MTX is a common example (category D evidence). Anakinra has been used with other effective DMARDs (category D evidence (abstract)). ${ }^{48}$

The use of ILl blocking agents as the first DMARD for the treatment of RA should, at present, be limited because these compounds are expensive and one needs to include cost considerations along with those of efficacy, effectiveness, and long term safety (category D evidence).

\section{Clinical use}

ILl blocking agents can lead to significant, documentable improvement in symptoms, signs, and/or laboratory parameters within 2-16 weeks (category A evidence). ${ }^{46} 4749$ Measures of patient related outcomes such as the patient's global VAS or HAQ may be more sensitive to the effects of one ILl blocking agent (Anakinra) than physical measures such as joint tenderness/swelling (category D evidence (abstract)). ${ }^{50}$ These measures of response should be followed up and individually important responses should be demonstrated within 8-16 weeks (category A evidence). ${ }^{46451}$ If clinically important improvement occurs, treatment should be continued (category D evidence).

There are data showing that ILl blocking agents, of which Anakinra is the marketed prototypic compound, slows radiographic progression in rheumatoid arthritis (category A evidence)..$^{46}$

Reactions at the injection site related to dose and affecting up to $70 \%$ of patients have occurred with the use of Anakinra. These reactions often do not require treatment and seem to moderate with continued use in some patients (category A evidence $^{46}{ }^{47} 49$; category D evidence (abstract $)^{48}$ ).

There are no data to advise either termination or continuation of ILl blocking agents if a patient becomes pregnant.

The efficacy and toxicity of ILl blocking compounds in rheumatic diseases other than RA are unknown.

\section{Warnings}

Possibly, there is a small increased incidence of infections, including serious infections, when using ILl blocking compounds. Therefore, these compounds should not be started or should be discontinued when serious infections occur $^{45-4749}$ (category A evidence ${ }^{46} 474951$; category D evidence (abstract $)^{48}$ ). Treatment with ILl blocking therapy in such patients should only be resumed if the infections have been adequately treated (category $\mathrm{D}$ evidence).

\section{Precautionary statements}

The safety of ILl for use in RA is unknown or has not been established in the following situations:

I Lymphoma, lymphoproliferative and other malignancies

2 During pregnancy or lactation, or both

3 When using ILl blocking agents and TNF blocking agents together; in combination with other biological agents/targeted therapy, such as TNF blocking agents, infections are common and serious infections have occurred and this combination should be used with great caution until new data become available (category D evidence (abstract) ${ }^{45}$ ) 
4 When considering primary vaccinations or live attenuated vaccines

Other areas where knowledge is lacking are highlighted in the consensus group's recommendations for areas most urgently requiring further research.

\section{Research}

Among a number of potential areas requiring action and/or further research, the consensus groups felt the following projects or directions were most important in each of four areas: registries, efficacy, toxicity, and general issues.

\section{Registry}

1 Long term registries to monitor the toxicity of biological agents are strongly recommended, requiring a cooperative effort among payers, government, industry, and rheumatologists.

2 It would be appropriate to convene a workshop to create common standards for such registries and to have a forum for comparisons of results.

3 Registries of pregnancy outcomes in patients receiving ILl blocking therapy (and after therapy has ended) should be continued.

4 What standards are required for long term trials and observational studies of ILl blocking agents? What are the outcomes of such studies in relationship to control subjects not taking ILl-blockers?

\section{Efficacy}

1 What is the efficacy of ILl blocking agents in patients who have used TNF blockers but have not responded or have not responded sufficiently?

2 What is the efficacy of ILl blocking agents in polyarticular juvenile arthritis and other rheumatic diseases, including osteoarthritis?

3 Do TNF blocking agents have an effect on pain?

\section{Toxicity}

l Can ILl blocking agents be used in patients who cannot be treated with TNF blocking agents because they have a history of tuberculosis or latent tuberculosis and cannot tolerate appropriate treatment for the latter, for some reason?

\section{Summary}

ILl blocking agents, of which Anakinra is the prototypic and sole example, are effective for the treatment of RA but their specific place (for example, before, after, or with TNF blocking agents) in the rheumatological armamentarium is not yet defined. Publication of studies in selected areas of efficacy, toxicity, and general use of ILl blocking agents are needed to help define further the most appropriate use of these agents. Further considerations when using ILl receptor antagonists in this disease must include the cost and recognition that data in subgroups of patients are still being acquired. It is hoped that this statement, which is based upon the best evidence available at the time of its creation, and modified by expert opinion, will facilitate the optimal use of ILl receptor antagonists for our patients with RA.

\section{APPENDIX 1 ABBREVIATED SUMMARY OF THE "UPDATED CONSENSUS STATEMENT ON BIOLOGICAL AGENTS FOR THE TREATMENT OF RA AND OTHER RHEUMATIC DISEASES-TNF BLOCKING AGENTS SUBSECTION"}

- Rheumatologists and bioscientists from numerous countries met to develop the consensus statement.

- A new consensus statement was required because additional information has corroborated the major positive effect of these drugs and possible new and unexpected adverse events have occurred.

- The process included a review of all relevant clinical published articles and, through an iterative process, the reaching of consensus.

- Individual patients differ in many aspects of their disease so one must frequently individualise treatment.

- TNF blocking agents differ in many ways, but this document emphasises areas of commonality, until clear differences can be shown among TNF blockers.

Indications

- TNF blockers are recommended for the treatment of active RA after using another DMARD (MTX is the most common of several DMARDs frequently used).

- TNF blocking agents can be added to pre-existing treatment or, when appropriate, may replace previous DMARDs or other biological agents.

- TNF blockers are effective in MTX-naive patients.

- At present, TNF blocking agents as the first DMARD for the treatment of RA should be limited because of considerations of long term safety. The cost should be included when considering the use of TNF blocking agents.

- When other DMARDs are relatively contraindicated, TNF blockers may be considered as the first DMARD.

- One TNF blocking agent has been approved for juvenile idiopathic arthritis of the polyarticular type as well as for psoriatic arthritis.

- TNF blockers are efficacious in ankylosing spondylitis.

- There is no evidence that any one TNF blocking agent should be used before another or that any TNF blocker is more effective than another, although individual differences may exist between patients.

- TNF blocking agents are being evaluated in Wegener's granulomatosis, giant cell arteritis, Takayasus arteritis, adult onset Still's disease, Sjögren's syndrome, hepatitis C, Behçet's disease, uveitis, polymyositis, systemic sclerosis, and other conditions, although more work is needed in all cases.

- Pharmacoeconomic and long term safety data may modify all of the above statements.

Clinical use

- When used in adequate doses and sufficiently frequent dosing regimens, TNF blocking agents should lead to significant, documentable improvement within 12 weeks for RA.

- The ACR response criteria (as a combined index) should not be used to monitor individual response; other validated quantitative measures such as the DAS, HAQ-DI, VAS, Likert scales, joint tenderness and/or swelling, and laboratory data may be more appropriate measures for individual patients.

- If documentable significant improvement occurs, treatment should be continued.

- If patients show no response to these agents treatment should be stopped.

- If an incomplete response occur, increased doses or reduced dosing intervals may provide additional benefits as may other DMARDs or other biological agents, although further study of this issue is required.

- TNF blocking agents slow radiographic progression in RA. Until the long term implications of this slowing are clear, radiological changes alone should not determine clinical decision-making. 


\section{Warnings}

- Insufficient data are available about the use of anti-TNF therapy during pregnancy to allow advice in this circumstance, although pharmacovigilance data have shown the same rate of normal births, miscarriages, and therapeutic terminations as in the general population.

- In the rare cases when lupus-like symptoms develop, TNF blocking agents should be stopped.

- The presence or development of a positive ANA, aCL, and/or dsDNA does not increase the risk of developing druginduced lupus.

- TNF blocking agents should not be started or should be discontinued when serious infections occur.

- Previous tuberculosis may be reactivated in patients given TNF blockers; individual evaluations, including history and physical examinations should be done and treatment for latent tuberculosis considered, according to local recommendations.

- When severe congestive heart failure is present TNF blockade should be used with caution.

- Instances of demyelinating-like disorders have been reported in patients receiving TNF blockers. These agents should be stopped if a demyelinating-like disorder occurs.

- Patients with a history of a definite demyelinating disease should not receive TNF blocking agents.

- A very few instances of pancytopenia and aplastic anaemia have been reported, although the relationship and incidence of this adverse event is not sufficiently understood to make specific recommendations about monitoring at this time.

- If pancytopenia or aplastic anaemia occurs, TNF blockers should be stopped in patients evaluated for evidence of other underlying disease.

\section{Precautionary statements}

- The safety of TNF blockade is unknown in the following situations: lymphomas and similar illnesses; chronic infections including HIV and chronic hepatitis; during pregnancy or lactation; when considering primary vaccinations or live attenuated vaccines.

\section{APPENDIX 2 ABBREVIATED SUMMARY OF THE “UPDATED CONSENSUS STATEMENT FOR THE USE OF BIOLOGICAL AGENTS IN THE TREATMENT OF RA AND OTHER RHEUMATIC DISEASES-IL1 BLOCKING AGENTS SUBSECTION"}

- Rheumatologists and bioscientists from numerous countries met to develop the consensus

- A new consensus statement was required because ILl blocking agents are beginning to appear, and possible new and unexpected adverse effects have occurred.

- The process included a review of all relevant clinical published articles and, through an iterative process, the reaching of consensus.

- Biological agents may differ in many ways, although there is presently only one prototypic agent, Anakinra, representing the ILl blocking agents.

\section{Indications}

- ILl blocking agents may be used, alone or with MTX, for the treatment of active RA. In Europe, ILl blocking agents (Anakinra) should presently be used in conjunction with MTX.

- ILl blocking agents will probably be effective when used with other effective DMARDs.
Clinical use

- ILl blocking agents (Anakinra) can lead to significant documentable improvement in symptoms, signs and/or laboratory measures within 2-16 weeks.

- Response measures should be followed up and individually important responses should be demonstrated within 8-16 weeks.

- If clinically important response to ILl blocking agents occurs, the agent(s) should be continued.

- ILl blocking agents (Anakinra) slow radiographic progression in RA.

- Reactions at injection site occur in up to $70 \%$ of patients in a dose-response manner. These injection site reactions often do not require treatment and may diminish with continued use.

- There are no data to advise continuation or termination of ILl blocking therapy if the patient becomes pregnant.

- The efficacy and toxicity of ILl blocking agents in rheumatic diseases other than RA are unknown.

\section{Warnings}

- Possibly, there is a small increased incidence of infections, including serious infections, when using ILl blocking agents.

- ILl blocking agents should not be started or should be discontinued when serious infections occur.

- Treatment with ILl blocking agents should only be resumed if infections have been adequately treated.

\section{Precautionary statements}

- The safety of ILl blocking agents is unknown or has not been established in the following situations: lymphoma, lymphoproliferative disease or other malignancies; pregnancy and/or lactation; in combination with other biological agents, including TNF blocking agents (where great care should be taken if these drugs are used together); when using primary vaccinations or live attenuated vaccines.

\section{APPENDIX 3 EVIDENCE SCHEME}

Category A evidence: Based on evidence from at least one randomised controlled trial or on the meta-analyses of randomised controlled trials.

Category B evidence: Based on evidence from at least one controlled trial without randomisation or at least one other type of experimental study or on extrapolated recommendations from randomised controlled trials or meta-analyses.

Category $C$ evidence: Based on non-experimental descriptive studies, such as comparative studies, correlational studies, and case-control studies, which are extrapolated from randomised controlled trials, non-randomised controlled studies, or other experimental studies.

Category D evidence: Based on expert committee reports or opinions or clinical experience of respected authorities, or both, or on extrapolated recommendations from randomised controlled trials, meta-analyses, non-randomised controlled trials, experimental studies or non-experimental descriptive studies.

Note: Abstracts have not been considered in the above evidence scheme, as they are not complete and may change by the time the data are published, or may not be published as full papers at all. Evidence from abstracts alone, therefore, is considered as category D evidence and noted as "abstract" until those data are published as a complete, peer reviewed paper.

\section{Authors' affiliations}

D E Furst, University of California, Los Angeles, CA, USA

F C Breedveld, Department of Rheumatology, Leiden University Medical Centre, Leiden, The Netherlands 
J R Kalden, Medizinische Klinik III, Friedrich Alexander Universität, Erlangen, Germany

J S Smolen, Abteilung für Rhumatologie, Universitätsklinik für Innere Medizin III, Wien, Austria

C E Antoni, Medizinische Klinik III, Friedrich Alexander Universität, Erlangen, Germany

J W J Bijlsma, Department of Rheumatology, University Medical Centre Utrecht, Utrecht, The Netherlands

G R Burmester, Department of Rheumatology and Clinical Immunology, Charité Hospital, Berlin, Germany

B Cronstein, New York University School of Medicine, New York, NY, USA

E C Keystone, Department of Rheumatology, Mount Sinai Hospital, Toronto, Ontario, Canada

A Kavanaugh, Division of Rheumatology, University of California, San Diego, La Jolla, CA, USA

L Klareskog, Rheumatology Unit, Department of Medicine, Karolinska Hospital, Stockholm, Sweden

Correspondence to: Dr D E Furst, 1000 Veteran Avenue Rehabilitation Center, Room 32-5, Los Angeles, CA 90024, USA;

defurst@mednet.ucla.edu

\section{REFERENCES}

1 Consensus group. Updated consensus statement on tumour necrosis factor blocking agents for the treatment of rheumatoid arthritis and other rheumatic diseases (April 2001). Ann Rheum Dis 2001;60(suppl III):iii2-5.

2 Shekelle PG, Woolf SH, Eccles M, Grimshaw J. Clinical guidelines: developing guidelines. BMJ 1999;318:593-6.

3 Wolfe F, Pincus T, O'Dell J. Arthritis disease status in the clinic: which variables best predict change in therapy? J Rheumatol 2001;28:1712-17.

4 Bathon JM, Martin RW, Fleischmann RM, Tesser JR, Schiff MH, Keystone $\mathrm{EC}$, et al. A comparison of etanercept and methotrexate in patients with early rheumatoid arthritis. N Engl J Med 2000;343:1586-93.

5 Elliott MJ, Maini RN, Feldmann M, Long-Fox A, Charles P, Katsikis $P$, et al. Treatment of rheumatoid arthritis with chimeric monoclonal antibodies to tumor necrosis factor alpha. Arthritis Rheum 1993:36:1681-90.

6 Elliott MJ, Maini RN, Feldmann M, Long-Fox A, Charles P, Bijl H, et al. Repeated therapy with monoclonal antibody to tumour necrosis factor alpha (cA2) in patients with rheumatoid arthritis. Lancet 1994:344:11 125-7.

7 Elliott MJ, Maini RN, Feldmann M, Kalden JR, Antoni C, Smolen JS, et al. Randomised double-blind comparison of chimeric monoclonal antibody to tumour necrosis factor alpha (cA2) versus placebo in rheumatoid arthritis. Lancet 1994;344:1 105-10.

8 Furst DE, Keystone E, Maini RN, Smolen JS. Recapitulation of the round-table discussion - assessing the role of anti-tumor necrosis factor therapy in the treatment of rheumatoid arthritis. Rheumatology (Oxford) 1999;38(suppl 2):50-53

9 Garrison L, McDonnell ND. Etanercept: therapeutic use in patients with rheumatoid arthritis. Ann Rheum Dis 1999;58(suppl I):165-9.

10 Harriman G, Harper LK, Schaible TF. Summary of clinical trials in rheumatoid arthritis using infliximab, an anti-TNF(alpha) treatment. Ann Rheum Dis 1999;58(suppl I):161-4.

11 Jones RE, Moreland LW. Tumor necrosis factor inhibitors for rheumatoid arthritis. Bull Rheum Dis 1999;48:1-3.

12 Kavanaugh AF. Anti-tumor necrosis factor alpha monoclonal antibody therapy for rheumatoid arthritis. Rheum Dis Clin North Am 1998;24:593-614

13 Lipsky PE, van der Heijde DMFM, St Clair EW, Furst DE, Breedveld FC, Kalden JR, et al. Infliximab and methotrexate in the treatment of rheumatoid arthritis. N Engl J Med 2000;343:1594-602.

14 Markham A, Lamb HM. Infliximab. A review of its use in the management of rheumatoid arthritis. Drugs 2000;59:1341-59.

15 Maini RN, Breedveld FC, Kalden JR, Smolen JS, Davis D, Macfarlane JD, et al. Therapeutic efficacy of multiple intravenous infusions of anti-tumor necrosis factor alpha monoclonal antibody combined with low-dose weekly methotrexate in rheumatoid arthritis. Arthritis Rheum 1998;41:1552-63

16 Moreland LW, Schiff MH, Baumgartner SW, Tindall EA, Fleischmann RM, Bulpitt KJ, et al. Etanercept therapy in rheumatid arthritis. A randomized controlled trial. Ann Intern Med 1999:130:478-86.

17 Moreland LW, Margolies G, Heck Jr. LW, Saway A, Blosch C, Hanna $R$, et al. Recombinant soluble tumor necrosis factor receptor $(p 80)$ fusion protein: toxicity and dose finding trial in refractory rheumatoid arthritis. Rheumatol 1996;23:1849-55.

18 Cush JJ, Spiera R. Etanercept update on recent "dear doctor" safety letter. ACR Hotline Dec 5, 2000.

19 Bray VJ. The safety of infliximab infusion in clinical practice. Arthritis Rheum 2001;44(suppl):S83 (abs 183).

20 Lovell DJ, Giannini EH, Reiff A, Cawkwell GD, Silverman ED, Nocton JJ, et al. Etanercept in children with polyarticular juvenile rheumatoid arthritis. N Engl J Med 2000;342:763-9.

21 Jarvis B, Faulds D. Etanercept. A review of its use in rheumatoid arthritis. Drugs 1999;57:945-66.

22 Mease P, Goffe B, Metz J, VanderStoep A, Finck B, Burge DJ. Etanercept in the treatment of psoriatic arthritis and psoriasis. Lancet 2000;356:385-90.
23 Braun J, Brandt J, Listing J, Zink A, Alten R, Golder W, et al. Treatment of active ankylosing spondylitis with infliximab: a randomised controlled multicentre trial. Lancet 2002;359:1 187-93.

24 Baeten D, Demetter P, Kruithof E, et al. Effect of TNF alpha blockade on synovial histology in spondyloarthropathy. Arthritis Rheum 2000;43(suppl): S404 (abs 2022).

25 Gorman JD, Sack KE, Davis JC, et al. Etanercept in the treatment of ankylosing spondylitis: a randomized, double-blind, placebo-controlled study. Arthritis Rheum 2000;44(suppl):S403 (abs 2020).

26 Brandt J, Haibel H, Reddig J, et al. Anti-TNF alpha treatment of patients with severe ankylosing spondylitis - a one year follow-up. Arthritis Rheum 2000;44(suppl):S403 (abs2021)

27 Weinblatt ME, Maier Al, Overman SS, et al. Etanercept in Still's disease in the adult. Arthritis Rheum 2000;43(suppl)::S391 (abs 1949).

28 Kraetsch HG, Antoni C, Kalden JR, Manger B. successful treatment of a small cohort of patients with adult onset of Still's disease with infliximab. Arthritis Rheum 2001;44(suppl):S1 18 (abs 395).

29 Rozenbaum M, Rosner I, Portnoy E. Remission of Behçet's syndrome with TNF alpha blocking treatment. Ann Rheum Dis 2002;61:283-4.

30 Sfikakis PP, Theodossiadis PG, Katsiari CG, Kaklamanis P, Markomichelakis NN. Effect of infliximab on sight threatening pan uveitis in Behcet's disease. Lancet 2001;358:295-6.

31 Steinfeld SD, Demols P, Salmon I, Kiss R, Appelboom T. Infliximab in patients with primary Sjögren's syndrome: a pilot study. Arthritis Rheum 2001;44:2371-5.

32 Hengstman G, van den Hoogen F, ven Engelen B, et al. Anti-TNF blockade with infliximab (Remicade) in polymyositis and dermatomyositis. Arthritis Rheum 2000;43(suppl):S193 (abs 748).

33 Ellman MH, MacDonald PA, Hayes FA. Etanercept S. treatment for diffuse scleroderma: a pilot study. Arthritis Rheum 2000;43(suppl):S392 (abs 1955).

34 Schiff $\mathbf{M}$, Mease $P$, Weinblatt $M$, et al. Randomized controlled trial of 25 $\mathrm{mg}$ vs. $50 \mathrm{mg}$ enbrel (etanercept) twice weekly in rheumatoid arthritis (RA). Arthritis Rheum 2000;43(suppl):S391 (abs 1947).

35 Genovese M, Martin R, Fleischmann R, et al. Enbrel (etanercept) vs methotrexate (MTX) in early rheumatoid arthritis (ERA trial): two-year follow-up. Arthritis Rheum 2000;43(suppl):S269 (abs 1217).

36 Shergy WJ, Phillips Jr RM, Hunt RE, Hernandez J. Safety and efficacy of infliximab therapy after etanercept failure: a case series. Arthritis Rheum 2001;44(suppl):S81 (abs 174).

37 Maksymowych WP, MallonC, Spady B, Peerani R, and the Alberta Capital Health Region. Intent in rheumatoid arthritis prospective observational inception cohort: efficacy, adverse events and withdrawal. Arthritis Rheum 2001;44(suppl):S82 (abs 175).

38 Wassermann MJ, Weber D, Bykerk V, Lee P, Keystone EC. Efficacy of infliximab ( $3 \mathrm{mg}$ per kilogram) in a population of severe, long-standing RA patients treated in a of quarternary care center. Arthritis Rheum 2001;44(suppl):S82 (abs 177)

39 Van Vollenhoven RF, Gullstrom E, Brannemark S, Klareskog L. Dose escalation of infliximab in clinical practice. Data from the Stockholm TNF alpha registry. Arthritis Rheum 2001:44(suppl):S82 (abstract 178)

40 Antoni CE, Furst D, Manger B, Lichtenstein GR, et al. Outcome of pregnancy in women receiving infliximab for the treatment of Crohn's disease or rheumatoid arthritis. Arthritis Rheum 2001;44(suppl):S152 (abs 600).

41 Hanaver SB. Review article: safety of infliximab in clinical trials. Aliment Pharmacol Ther 1999;13:16-22.

42 Keane J,Gershom S, Wise RP, Mirabile-Levens E, Kasznica J, Schwieterman WD, et al. Tuberculosis associated with infliximab, a tumor necrosis factor alpha neutralizing agent. $\mathrm{N}$ Engl J Med 2001;345:1098-104

43 Mohan N, Edwards ET, Cupps TR, Oliverio PJ, Sandberg G, Crayton H, et al. Demyelination occurring during antitumor necrosis factor alpha therapy for inflammatory arthritides. Arthritis Rheum 2001;44:2862-9.

44 Peterson JR, Wener MH, Hsu FC, Simkin PA. Safety of TNF alpha antagonists in patients with rheumatoid arthritis and chronic hepatitis $\mathrm{C}$. Arthritis Rheum 2001; 44(suppl):S78 (abs 156).

45 Schiff MH, Bulpitt K, Weaver AA, Genovese M, Cohen S, Furst DE, et al. Safety of combination therapy with anakinra and etanercept in patients with rheumatoid arthritis. Arthritis Rheum 2001;44(suppl):S79 (abs 157).

46 Breshnihan B, Alvaro-Gracia JM, Cobby M, Doherty M,Domijan Z, Emery $P$, et al. Treatment of rheumatoid arthritis with recombinant human interleukin-1 receptor antagonist. Arthritis Rheum 1998;41:2196-204.

47 Cohen S, Hurd E, Cush J, Schiff M, Weinblatt M, Moreland LW, et al. Treatment of rheumatoid arthritis with Anakinra, a recombinant human interleukin-1 receptor antagonist, in combination with methotrexate. Arthritis Rheum 2002;46:614-24.

48 Fleischman R, Tesser J, Schechtman J, Modaferri D, Poulakos J, Bennett $R$, et al. A safety trial of Anakinra, recombinant IL-1 ra, in a large, placebo controlled, heterogenous population of patients with rheumatoid arthritis. Arthritis Rheum 2001;44(suppl):S84 (abs 190).

49 Dayer J-M, Breshnihan B. Targeting interleukin-1 in the treatment of rheumatoid arthritis. Arthritis Rheum 2002;46:574-8

50 Cohen S, Nakelsky S, Mulani P, Badamgarav E, Harada A, Sokolskiy L, et al. The impact of Anakinra therapy on patient centered outcomes in rheumatoid arthritis. Arthritis Rheum 2001;44(suppl):S77 (abs 149).

51 Jian Y, Genant HK, Watt I, Cobby M, Breshnihan B, Aitchison R, McCabe D. A multicenter, double-blind, dose ranging, randomized, placebo-controlled study of recombinant human interleukin-1 receptor antagonist in patients with rheumatoid arthritis: radiologic progression and correlation of Genant and Larsen scores. Arthritis Rheum 2000;43:1001-9. 